\title{
Modeling of the structural impact of seismically isolated buildings
}

\author{
P. Polycarpou, L. Papaloizou, P. Komodromos \& M. C. Phocas \\ Department of Civil and Environmental Engineering, \\ University of Cyprus, Nicosia, Cyprus
}

\begin{abstract}
Structural impact can be considered using methods that are based on either stereomechanical or force-based approaches. The force-based approach, which uses contact springs that are automatically formed during impact, is more suitable for simulations of multiple deformable bodies, such as colliding buildings. After making a comparison among the most common impact models of the force-based approach, a modified impact model is proposed as a variation of the linear viscoelastic impact model (Kelvin-Voigt). The modified viscoelastic impact model avoids tensile impact forces during detachment and enables the consideration of permanent plastic deformations due to poundings. The proposed impact model is used for simulations of poundings of seismically isolated buildings with adjacent structures, in order to assess the influence of potential structural impact on the effectiveness of seismic isolation. Poundings are assumed to occur at the isolation level between the seismically isolated building and the adjacent moat wall whenever the available seismic gap is exceeded due to a strong earthquake excitation. The simulations reveal that poundings may substantially increase floor accelerations, especially at the floor where impacts occur, and excite higher modes of vibration, increasing the interstory deflections. Keywords: poundings, structural impact, seismic isolation, seismic gap.
\end{abstract}

\section{Introduction}

Seismic isolation introduces flexibility, or a sliding mechanism, at the isolation level of a relatively stiff building, shifting its fundamental period outside the dangerous for resonance range, or preventing the transmission of a shear force higher than a certain value, in order to reduce the induced seismic loads. 
A practical constraint in the implementation of seismic isolation is the wide seismic gap that must be provided as a clearance around the building to facilitate the expected large relative displacements at the isolation level. Considering that there are often certain practical restrictions to the size of the available clearance around seismically isolated buildings, a reasonable concern is the possibility of poundings with adjacent structures during very strong earthquakes.

A critical aspect in numerical simulations of structural pounding is the impact model that is employed and the values of the associated parameters, which affect the computed results. In most research studies on structural pounding, forcebased impact models are used, exerting impact forces to the colliding structures whenever their separation distances are exceeded. Anagnostopoulos [1], Jankowski [2], Muthukumar and DesRoches [3] and others have proposed various methodologies using either a linear or a non-linear impact spring together with an energy dissipation mechanism to model structural pounding. However, none of these impact models takes into account the remaining plastic deformations of the colliding structures.

Following a brief description of the simulation approach, the most commonly used impact models are assessed, leading to a proposed variation of the linear viscoelastic impact model. Subsequently, selected simulation results are presented with emphasis placed on the influence of the impact modelling and the values of the corresponding parameters.

\section{Description of the problem}

Poundings are assumed to happen between the moat wall and the base mat at the isolation level, which is the most common case of structural impact for a seismically isolated building due to the large relative displacements at the isolation level. The superstructure is modeled as a multi-degree of freedom system with shear-beam behavior and the masses lumped at the floor levels (fig. 1(a)).

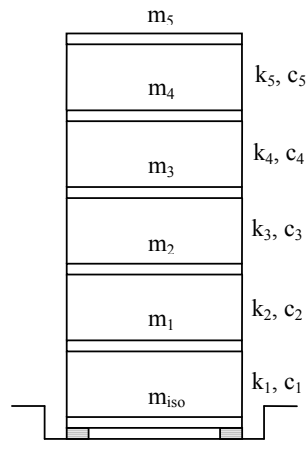

(a)

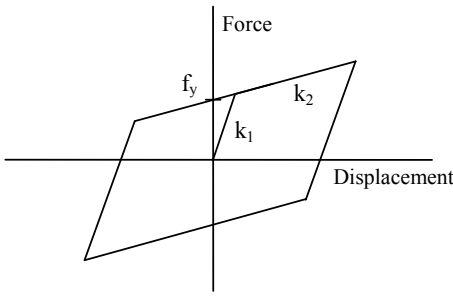

(b)

Figure 1: (a) Analysis model of the seismically isolated structure; (b) the bilinear model considered for the isolation system.

A bilinear behaviour is considered for the isolation system (fig. 1(b)), with additional viscous damping, while the superstructure is assumed to remain elastic 
during earthquake excitations. The equations of motion are formed considering all inertia, damping and elastic forces, while the impact forces are taken into account only during poundings. Impact is considered assuming an impact spring and an impact dashpot in parallel, which exert impact forces to the colliding structures whenever their separation distances are exceeded. At each time step the equations of dynamic equilibrium are directly integrated using the Central Difference Method (CDM), computing the displacements and other response quantities at the following time step.

\section{Impact modeling}

Structural impact is considered using force-based methods, also known as penalty methods. These methods allow interpenetration between the colliding structures, which is justified by their deformability at the vicinity of the impact. Contact springs are automatically formed when an impact is detected, kept as long as the building remains in contact with the moat wall and removed as soon as the building is detached from the wall. The interpenetration depth is used together with the stiffness of the contact spring to estimate, according to the impact model, the contact forces that are applied to the structures, pushing them apart.

In this work, both linear and non-linear impact models are used, in order to investigate the effect of the impact model selection on structural response with pounding incidences. Specifically, the Kelvin-Voigt model and the Hertzian model with non-linear damping were selected, using the formulas provided by Anagnostopoulos and Jankowski, respectively, for the estimation of the impactdamping coefficient. In addition, an adjustment to the Kelvin-Voigt model is proposed.

\subsection{Linear viscoelastic impact model}

The linear viscoelastic impact model, also known as Kelvin-Voigt model, is one of the most commonly used in structural pounding and consists of a linear impact spring and a viscous impact dashpot. Whenever there is impact, the impact force at time $t$ is provided by the expression:

$$
F_{\text {imp }}(t)=k_{\text {imp }} \cdot \delta(t)+c_{\text {imp }} \cdot \dot{\delta}(t)
$$

where $k_{i m p}$ is the stiffness of the linear impact spring, $\delta(t)$ is the interpenetration depth of the colliding bodies that overlap each other, $c_{i m p}$ is the impact-damping coefficient and $\dot{\delta}(t)$ is the relative velocity between the colliding structures at time $t$.

Anagnostopoulos [1] has provided the following analytical expressions that associate the impact-damping coefficient with the coefficient of restitution (COR) and the masses $m_{1}$ and $m_{2}$, of the colliding bodies:

$$
c_{i m p}=2 \cdot \xi_{i m p} \sqrt{k_{i m p} \frac{m_{1} \cdot m_{2}}{m_{1}+m_{2}}}
$$




$$
\xi_{\text {imp }}=-\frac{\ln (C O R)}{\sqrt{\pi^{2}+(\ln (C O R))^{2}}}
$$

where $\xi_{\text {imp }}$ is the impact damping ratio $\left(0<\xi_{i m p}<1\right)$. The COR is defined as the ratio of the relative velocities between the colliding bodies after and before $\operatorname{impact}(0 \leq C O R \leq 1)$. The derivation of the above formulas is based on the conservation of energy. However, this model exhibits an initial jump of the impact force values upon impact due to the damping term. Furthermore, the damping force causes negative impact forces that pull the colliding bodies together, during the unloading phase, instead of pushing them apart (fig. 2(a)). Nevertheless, as it is shown later, this simple impact model provides sufficiently accurate results for the overall structural response, given that proper values are used for the impact parameters.

\subsection{Non-linear viscoelastic impact model}

Another commonly used structural impact model uses a non-linear impact spring, based on Hertz's contact law. According to this model, it is assumed that the impact force increases exponentially with the interpenetration depth, usually with an exponent of 1.5. In order to include an energy dissipation mechanism, some researchers $[2,3]$ have incorporated a non-linear damper parallel to the non-linear spring during the approach phase of the contact (fig. 2(b)). In that case the impact force during the approach phase equals:

$$
F_{\text {imp }}(t)=\hat{k}_{\text {imp }} \cdot \delta(t)^{1.5}+\hat{c}_{\text {imp }}(t) \cdot \dot{\delta}(t)
$$

while during the restitution phase, the energy dissipation is omitted and the impact force equals:

$$
F_{i m p}(t)=\hat{k}_{i m p} \cdot \delta(t)^{1.5}
$$

According to Jankowski [2], the impact-damping coefficient $\hat{c}_{i m p}(t)$ is provided by the following formula in terms of the impact damping ratio $\hat{\xi}_{\text {imp }}$ and the interpenetration depth $\delta(t)$ :

$$
\hat{c}_{i m p}=2 \cdot \hat{\xi}_{i m p} \sqrt{\hat{k}_{i m p} \cdot \sqrt{\delta(t)} \cdot \frac{m_{1} \cdot m_{2}}{m_{1}+m_{2}}}
$$

The impact-damping ratio $\hat{\xi}_{i m p}$ can be estimated using Jankowski's [4] formula:

$$
\hat{\xi}_{\text {imp }}=\frac{9 \sqrt{5}}{2} \frac{1-\operatorname{COR}^{2}}{\operatorname{COR}(\operatorname{COR}(9 \pi-16)+16)}
$$


The damping ratio, according to eq. (7), may take values greater than 1 and specifically approaches infinity for $C O R=0$ (perfectly plastic impact) [4], in contrary with the $\xi_{i m p}$ provided by eq. (3) for the linear viscoelastic impact model which takes values between 0 and 1 .

\subsection{Proposed impact model}

In order to avoid the tensile impact forces that arise between the colliding structures at the end of the restitution period, due to the damping term, a minor adjustment is proposed for the linear viscoelastic model. In particular, when the impact force is about to change sign, the impact spring and dashpot are removed, considering that the building is detached from the moat wall. The wall is kept at its current position, assuming some remaining plastic deformations, which increase the corresponding available width of the seismic gap (fig. 2(c)).

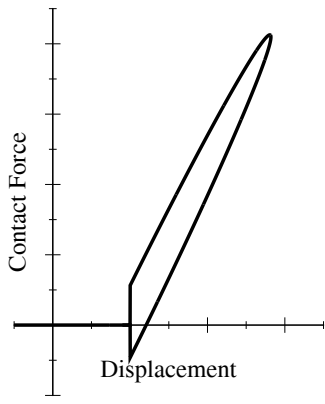

(a)

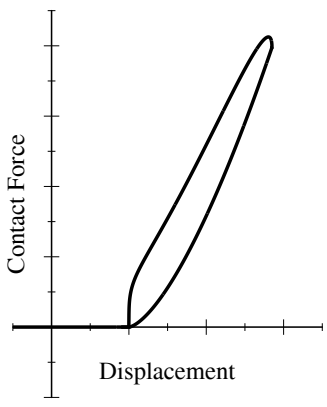

(b)

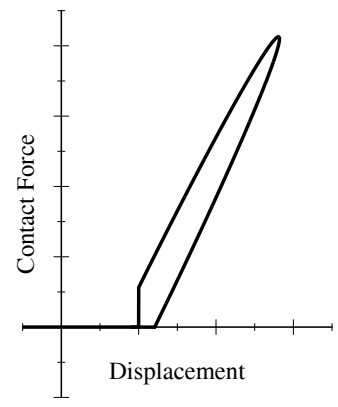

(c)

Figure 2: Impact models: (a) linear viscoelastic model; (b) non-linear viscoelastic model; and (c) the proposed modified linear viscoelastic model with permanent deformation.

Therefore, the equation that provides the impact force can be written as:

$$
F_{i m p}(t+\Delta t)=\left\{\begin{array}{cl}
k_{i m p} \cdot \delta(t)+c_{i m p} \cdot \dot{\delta}(t) & \text { when } \quad F_{\text {imp }}(t)>0 \\
0 & \text { when } F_{\text {imp }}(t) \leq 0
\end{array}\right.
$$

When using the force-based impact models, it is very important to appropriately determine a value for the impact stiffness, which depends on the mechanical properties of the material and the geometry of the contact surface of the colliding bodies. A wide range of diverse values has been used in the literature for different kinds of impact problems. Van Mier et al [8], who experimentally examined the case of impact between concrete bodies, concluded that the impact stiffness, considering a non-linear impact spring, should vary 
from 40 to $80 \mathrm{kN} / \mathrm{mm}^{1.5}$ in order to match experimental results. However, those values may not represent properly the impact forces that are applied during poundings of a large-scale building against a wall or another structure.

\section{Simulations and results}

\subsection{Example}

A typical seismically isolated building is used in the simulations in order to examine the pounding effects and the case of using different impact models. The superstructure is assumed to have 5 floors, each with a lamped mass of 500 tons, while each story has horizontal stiffness of $1 \mathrm{GN} / \mathrm{m}$. An additional mass of 500 tons is assumed to be lumped at the isolation level, while the bilinear properties of the isolation system were taken as follows (see fig. 1(b)): $\mathrm{k}_{1}=200 \mathrm{MN} / \mathrm{m}$, $\mathrm{k}_{2}=25 \mathrm{MN} / \mathrm{m}, \mathrm{f}_{\mathrm{y}}=0.1 \times \mathrm{W}_{\text {tot }}$, where $\mathrm{W}_{\text {tot }}$ is the total weight of the building. A damping ratio equal to $2 \%$ was assumed for the superstructure, while for the isolation system, in addition to the hysteretic energy dissipation, a 5\% viscous damping ratio was considered. The fundamental period of the fixed-supported superstructure is equal to $\mathrm{T}_{\text {fixed }}=0.494 \mathrm{sec}$.

The three previously described impact models (fig. 2) are used, to consider potential poundings of the isolated building with the moat wall. In particular, the linear viscoelastic model with impact stiffness equal to $k_{\text {imp }}=1250 \mathrm{kN} / \mathrm{mm}$, the Hertzian model with non-linear damping using as impact stiffness the value of $\hat{k}_{i m p}=277.8 \mathrm{kN} / \mathrm{mm}^{1.5}$ and the proposed modified viscoelastic model, which allows plastic deformations, with impact stiffness equal to $k_{\text {imp }}=1250 \mathrm{kN} / \mathrm{mm}$, are used. These values were selected in order to obtain the same maximum impact force when the base mat hits the wall with a constant velocity of $1 \mathrm{~m} / \mathrm{sec}$. The maximum impact force was calculated using a finite element analysis, simulating the collision of a concrete slab against a retaining wall with a velocity of $1 \mathrm{~m} / \mathrm{sec}$. For all models the COR was taken equal to 0.7 and the masses of the colliding bodies equal to 500 tons and 1000 tons for the base mat and the moat wall, respectively. For each of these cases, dynamic analysis of the building is performed under the Northridge 74 Sylmar-Converter Station record $(\mathrm{PGA}=$ $0.897 \mathrm{~g}$ ), which is a relatively very strong excitation.

According to the simulation results, the total accelerations as well as the interstory deflections and, therefore, the story shear forces of the seismically isolated building may significantly increase due to poundings that occur when the available seismic gap is exceeded. Peak values of interstory deflections and absolute floor accelerations are plotted in fig. 3, considering two different widths of the seismic gap, specifically $18 \mathrm{~cm}$ and $25 \mathrm{~cm}$, and compared with the corresponding values of the fixed-supported and base-isolated building without impact. In the case of poundings, interstory deflections and total floor accelerations become higher than the corresponding peak responses of the fixedsupported building (fig. 4). Due to poundings with the moat wall, the structure may experience maximum floor accelerations at the isolation level, instead at the top-floor of the building. It is evident that poundings may change the mode of 
deformation of a seismically isolated building, exciting higher modes of the structure, instead of moving as an almost rigid-body according to its fundamental mode.

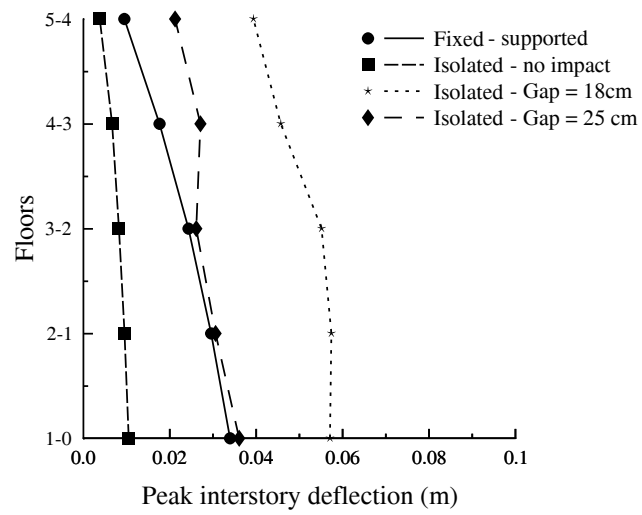

(a)

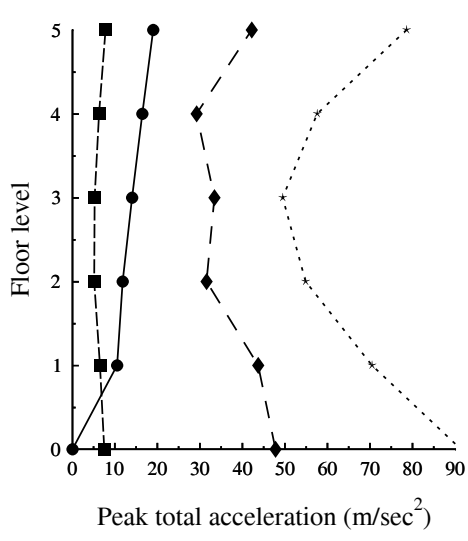

(b)

Figure 3: (a) Maximum interstory deflections; and (b) maximum absolute floor accelerations for the 5-story building under the Northridge earthquake.

The peak responses of the seismically isolated structure with the separation gap equal to $18 \mathrm{~cm}$ for the three impact models are presented in Table 1. In general, the differences are very small, as concerns the computed response.

Table 1: Peak responses of the 5-story structure under Northridge Earthquake with gap $=18 \mathrm{~cm}$ for the three different impact models.

\begin{tabular}{lccc}
\hline Peak Response & $\begin{array}{c}\text { Kelvin- } \\
\text { Voigt }\end{array}$ & $\begin{array}{c}\text { Hertzian } \\
\text { Viscoelastic }\end{array}$ & $\begin{array}{c}\text { Modified } \\
\text { Kelvin-Voigt }\end{array}$ \\
\hline Base floor displacement $[\mathrm{cm}]$ & 22.189 & 21.310 & 22.227 \\
Top floor displacement $[\mathrm{cm}]$ & 44.003 & 43.611 & 44.050 \\
Interstory deflection $[\mathrm{cm}]$ & 5.738 & 5.769 & 5.737 \\
Total acceleration (top floor) $\left[\mathrm{m} / \mathrm{sec}^{2}\right]$ & 78.856 & 75.451 & 78.553 \\
Total acceleration (base floor) $\left[\mathrm{m} / \mathrm{sec}^{2}\right]$ & 91.866 & 102.660 & 91.338 \\
Remaining plastic deformation $[\mathrm{cm}]$ & ---- & ---- & 0.412 \\
\hline
\end{tabular}


Acceleration response at the top floor

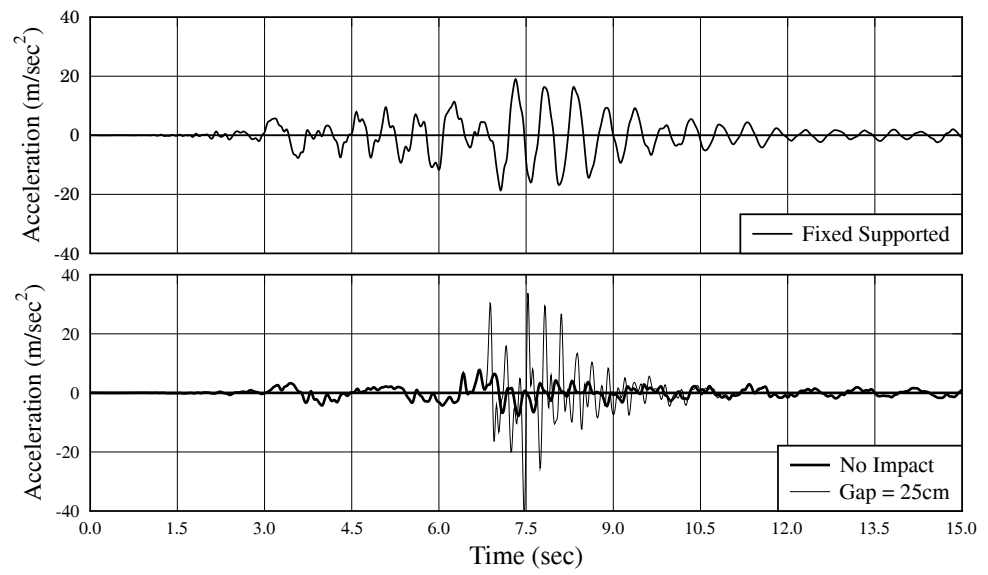

Figure 4: Acceleration time history response for Northridge earthquake.

\subsection{Parametric analysis}

The evaluation of the stiffness and damping parameters of the force-based impact models poses a major difficulty, as very limited experimental results are available to validate the proposed impact models. In order to examine the effect of the impact stiffness and the coefficient of restitution on the peak response of the seismically isolated building during poundings, a series of parametric studies has been performed.

In particular, fig. 5 shows the peak floor accelerations and interstory deflections of the 5-story seismically isolated building under the Northridge earthquake, assuming a seismic gap equal to $18 \mathrm{~cm}$ and considering the modified linear viscoelastic impact model to simulate poundings. Figure 6 shows the corresponding results using the Hertzian viscoelastic impact model. In general, for very low values of the impact stiffness, the response is increasing with $k_{i m p}$ for both linear and non-linear impact models. For higher values, the response remains almost insensitive to the variation of impact stiffness except for the acceleration response at the isolation level which substantially increases with this parameter.

The value of the coefficient of restitution also seems to affect the acceleration response at the isolation level, especially for the non-linear viscoelastic impact model. Specifically, for low values of COR (less than about 0.5) the damping ratio (eq. (7)) becomes larger than 1.0, rendering the impact highly overdamped and causing high local acceleration response during impact. In contrary, the corresponding plot for the linear viscoelastic impact model (fig. 5) shows that this effect of $C O R$ is not so pronounced. The rest of the response at the upper floors seems to be quite insensitive to the variation of the coefficient of restitution. 

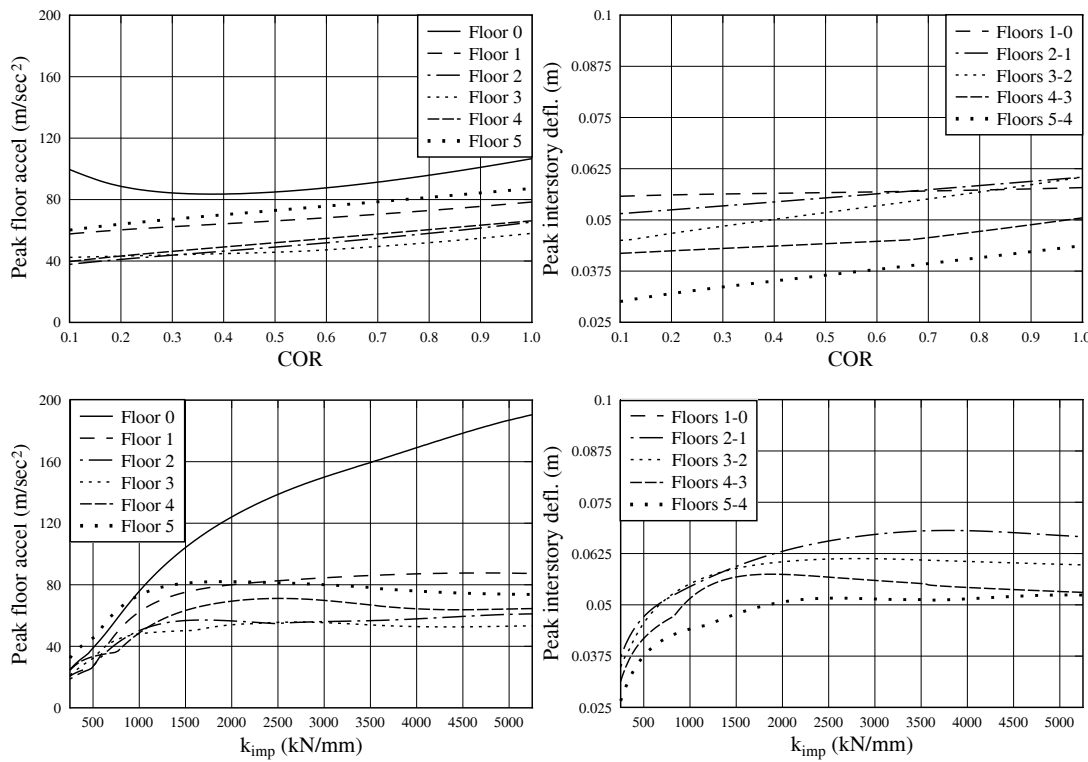

Figure 5: Influence of the coefficient of restitution $(C O R)$ and the impact stiffness $\left(k_{\text {imp }}\right)$ on the peak floor accelerations and interstory deflections considering the modified linear viscoelastic impact model.
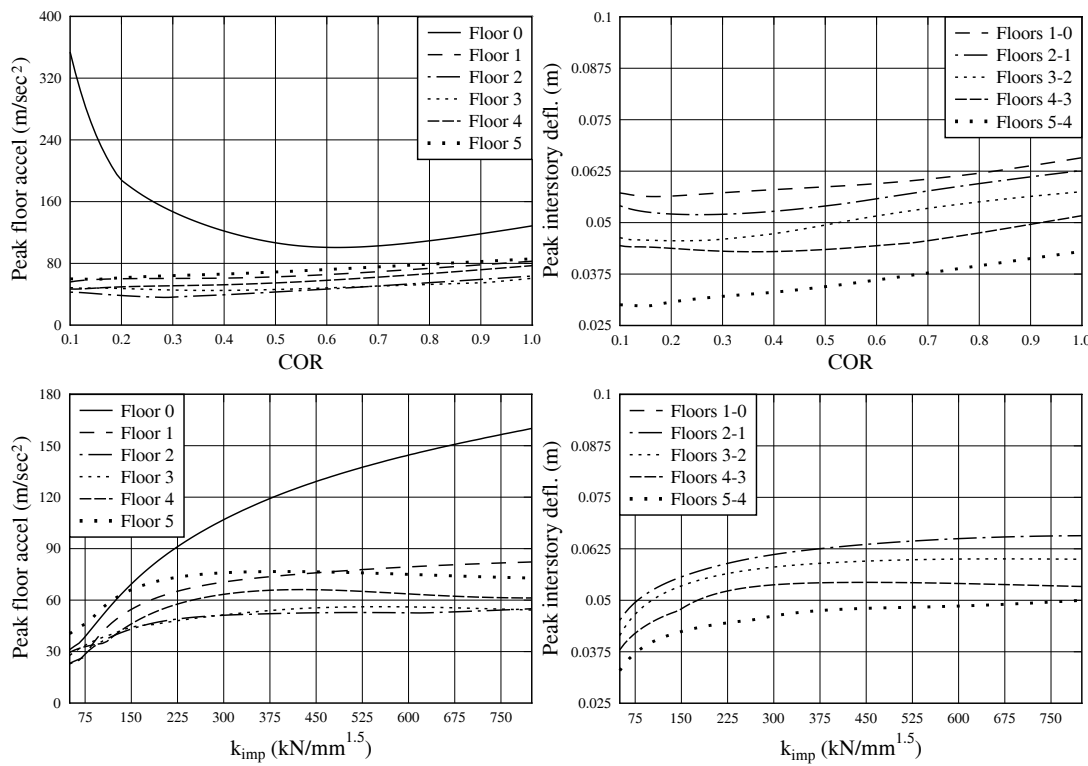

Figure 6: Effect of $C O R$ and $k_{\text {imp }}$ on the peak floor accelerations and interstory deflections considering the Hertzian viscoelastic impact model. 


\section{Conclusions}

Poundings substantially increase both floor accelerations and interstory deflections of seismically isolated buildings subjected to a strong seismic excitation. In the present study both the linear and the non-linear viscoelastic structural impact models are investigated and a modified impact model is proposed that takes into account remaining plastic deformations during poundings while avoiding tensile forces after detachment. The impact stiffness parameter, using both linear and non-linear impact models, seems to highly affect floor accelerations at the isolation level where impacts occur. The rest of the responses are slightly affected by the variation of impact stiffness after a certain value. Very low values for the coefficient of restitution increase substantially the peak floor accelerations at the level of impact when using the non-linear viscoelastic impact model.

\section{Acknowledgements}

The authors would like to thank the European Commission for funding the corresponding research proposal EIPOSIS\#014591 (Earthquake-Induced Poundings of Seismically Isolated Structures) under the Marie Curie IRG/ENG action of the FP6.

\section{References}

[1] Anagnostopoulos, S.A. Pounding of buildings in series during earthquakes. Earthquake Engineering and Structural Dynamics 1988, 16, pp. 443-456.

[2] Jankowski, R. Non-linear viscoelastic modelling of earthquake-induced structural pounding. Earthquake Engineering and Structural Dynamics, 34, pp. 595-611, 2005.

[3] Muthukumar, S. \& DesRoches, R. A Hertz contact model with non-linear damping for pounding simulation. Earthquake Engineering and Structural Dynamics, 35, pp. 811-828, 2006.

[4] Jankowski, R. Analytical expression between the impact damping ratio and the coefficient of restitution in the non-linear viscoelastic model of structural pounding. Earthquake Eng. and Struct. Dynamics, 35, pp. 517-524, 2006.

[5] Tsai, H.C. Dynamic analysis of base-isolated shear beams bumping against stops. Journal of Earthquake Engineering and Structural Dynamics, 26, pp. 515-528, 1997.

[6] Malhotra, P.K. Dynamics of seismic impacts in base-isolated buildings. Earthquake Engineering and Structural Dynamics, 26, pp. 797-813, 1997.

[7] Matsagar, V.A, Jangid, R.S. Seismic response of base-isolated structures during impact with adjacent structures. Engineering Structures, 25, pp. 1311-1323, 2003.

[8] Van Mier, J.G.M., Pruijssers, A.F., Reinhardt, H.W., Monnier, T. LoadTime Response of Colliding Concrete Bodies. Journal of Structural Engineering 1991; 117:354-374. 